\title{
Assessment of Structural and Functional Pulmonary Vascular Disease in Patients with PAH
}

\author{
Juan Grignola1, Enric Domingo ${ }^{2,3}$, \\ Rio Aguilar-Torres ${ }^{3,4}$ and Antonio Roman 5 \\ ${ }^{1}$ Dept Pathophysiology, Hospital de Clínicas, Universidad de la República, \\ ${ }^{2}$ Area del Cor, Hospital Universitari Vall d'Hebron \\ ${ }^{3}$ Dept Physiology, Universitat Autonoma Barcelona \\ ${ }^{4}$ Unit of Cardiac Image, Hospital Universitario Bellvitge \\ ${ }^{5}$ Servei de Pneumologia i CIBERES, Hospital Universitari Vall d'Hebron \\ ${ }^{1}$ Uruguay \\ 2,3,4,5 Spain
}

\section{Introduction}

Pulmonary arterial hypertension (PAH) is a life threatening disease characterized by a progressive increase in pulmonary blood pressure that often leads to right ventricular (RV) failure and death (McLaughlin et al., 2009). A review of the clinical trial data for the three classes of drugs approved for the treatment of PAH (prostanoids, endothelin antagonists, and phosphodiesterase-5 inhibitors) has shown that all agents have similar efficacy on the 6-min walking distance over 12 to 16 weeks, which was the primary endpoint in the randomized clinical trials. However, the improvement in the distance walked during the 6-min walking test in the patients receiving active therapy that led to drug approval ranged from 3 to 17\% from baseline. With respect to hemodynamics (which provides direct information about the status of the pulmonary circulation) these treatments are unimpressive, producing only a minimal reduction in the pulmonary arterial (PA) pressure. Presently, it remains speculative how these different drugs act on the pulmonary vasculature of patients with PAH and little is known about their long-term efficacy (Rich, 2006). Likewise, recent metaanalysis reported that the pooled effect of all treatment strategies shows a significant reduction of $39 \%(2-62 \%$, $\mathrm{p}=0.041$ ) in all-cause mortality (Galié et al., 2009). The benefits were confined only to patients with advanced disease for only 16 weeks, regardless of which class of drug was used. However, the mechanism by which mortality decrease remains unknown because it was unrelated to a specific class of drug, the dose of the drug, or the effects of the drug on 6-minute walking distance or hemodynamics (Macchia et al., 2010).

The increase in pulmonary arterial pressure in patients with PAH is due to the combination of pulmonary vasoconstriction, pulmonary arterial wall remodeling and in situ thrombosis. The structural and functional changes in the pulmonary arteries of patients with idiopathic PAH (IPAH) (vascular remodeling) include wall thickening of all three layers of the blood vessel 
wall (adventitia, media and intima) and reduction of the arterial lumen. This is an important pathological feature of PAH which leads to increased steady and pulsatile components of the pulmonary vascular load. Several studies have shown that the proliferation of PA smooth muscle cells in PAH is enhanced, whereas apoptosis is depressed. Among the drugs currently used for the treatment of patients with $\mathrm{PAH}$, it was demonstrated that prostacyclin analogues inhibit proliferation and promoting apoptosis to a greater extent in distal $(<1 \mathrm{~mm}$ external diameter) compared with proximal $(>8 \mathrm{~mm}$ external diameter) isolated human PA smooth muscle cells stimulating the cGMP pathway. These effects were potentiated by sildenafil in an independent cAMP pathway mechanism (Wharton et al., 2000, 2005). Recently, it was reported that imatinib (a tyrosine kinase inhibitor) also has anti-proliferative and pro-apoptotic effects on platelet-derived growth factor-stimulated PA smooth muscle cells from patients with IPAH (Nakamura et al., 2011). However, neither of the clinical trials characterize the direct effects of the treatments on the vasculature (eg, remodeling), until now. Direct measurement of PA structural/functional remodeling with new vascular imaging techniques such as cardiac magnetic resonance, intravascular ultrasound (IVUS) or optical coherence tomography (OCT) imaging needs to be investigated. Remarkable advances in these techniques provide an extraordinary opportunity to gain insight into histopathology that previously could only be obtained by open lung biopsy.

The aim of the present chapter is to evaluate the viscoelastic pulmonary artery properties (by IVUS) and PA fibrosis (by OCT) in patients with PAH and its relation to dynamic afterload. In addition, we also analyze acute vasoreactivity and its relationship with the viscoelastic properties of pulmonary artery vascular wall in patients with IPAH.

\section{Physiological basis of normal local arterial viscoelastic properties}

The viscoelastic properties of the great arteries determine their main functions: to conduct blood (conduction function) and to buffer the pulse pressure and flow generated by ventricular ejection (wall buffering function). In general, the elastic and viscous properties of the arterial wall have been characterized together as "viscoelasticity." Various studies have demonstrated that the elasticity and viscosity of the arterial wall play different roles in arterial function, and can also be independently affected by physiologic, pathologic or experimental conditions (Nichols \& O’Rourke, 2005).

Elasticity depends strongly on pressure and therefore increases significantly during increased arterial pressure. Elastin, collagen, and vascular smooth muscle have different elastic moduli. They all start to stretch at different levels of arterial wall strain, thus the ratio of pressure to diameter is non-linear. At higher pressure, the recruitment of more rigid collagen fibers is greater, and elasticity increases. The degree of activation of vascular smooth muscle also affected arterial elasticity. Elastin and collagen keep the level of arterial stress stable, which allows cyclic elastic arterial stretching and recovery but prevents overdistension and arterial wall disruption. In contrast, vascular smooth muscle is a dynamic component whose elasticity depends not only on the distension pressure but also on its extent of activation. The elastic response of the artery is an important determinant of its conduction and buffering functions. An adequate elastic modulus allows systolic distension of the artery and the subsequent diastolic elastic recoil, which ensures the continuous anterograde blood flow. In addition, an adequate elastic modulus reduces the oscillations generated by the heart, ensuring a high mean arterial pressure and a low pulsatility. 
Previous studies performed in systemic arteries and the PA showed that activation of vascular smooth muscle increases arterial wall elasticity as a function of deformation or diameter (isometric analysis), or decreases arterial stiffness as a function of strain or pressure (isobaric analysis). Our experimental data agree with these studies because elasticity, when measured at constant pressure, decreased with muscular activation (passive versus active $\mathrm{PH})$ (Bia et al., 2005a).

Arterial wall viscosity has been associated mainly with energy loss during the cardiac cycle and might be directly associated with the amount and degree of activation of vascular smooth muscle. We have demonstrated that only the activation of vascular smooth muscle increased viscosity with respect to the control value in both PA and aorta. Moreover, viscosity was greater in the aorta than in the PA during control and hypertensive states (Bia et al., 2003). The viscosity of arterial tissue might be explained by one of two theories (Nichols \& O'Rourke, 2005). The "passive» theory assumes that viscosity is a property of the constituents of the arterial wall (being vascular smooth muscle the most important). The «active» theory considers the mechanisms generating muscle contraction (activation) and myogenic response to stretching to be important. The viscous response of the arterial wall is independent of pressure and attenuates the highest frequency components of the incident waves of pressure and flow and the amplitude of the reflected waves that could trigger resonance phenomena in the system. A higher viscosity denotes a greater energy cost during the pulsatile expansion of the vessel in each cardiac cycle and is associated with a higher buffering function (Bia et al., 2005b).

Arterial wall buffering function could be defined by arterial wall viscosity/elasticity ratio. The arterial elasticity is highly dependent on blood pressure, and the viscosity values related to the amount of vascular smooth muscle and its degree of activation. Recently, in anesthetized animals, Bia et al found that the local wall buffering function of the ascending aorta and the main PA is similar despite their differences in elastic and viscous response. In both arteries, during active hypertension, the wall buffering function remained similar to the basal value, despite the increased pressure dependent upon the elastic modulus. This maintenance of the wall buffering function is due to the increase in the viscous modulus generated by the muscle activation (Bia et al., 2003).

\section{Intravascular ultrasound (IVUS): A functional approach for the evaluation of pulmonary arterial wall viscoelasticity in PAH}

In the clinical setting, the hemodynamic characterization of the pulmonary vascular tree and the response to vasoactive drugs is achieved by applying Poiseuille's law from pressure and cardiac output determinations during right heart catheterisation. However, these measurements have several limitations: a) they only assess the status of the stationary component of the pulmonary vasculature, neglecting the essentials of a pulsatile circulation; b) they correlate weakly with histological findings; and c) they do not have the ability to evaluate both structural and functional states of the PA wall (Saouti et al., 2010).

Resistance is only one component of afterload, and its calculations assume a constant blood flow, whereas compliance, capacitance and impedance are more useful to describe pulsatile flow. The PA stiffness assessment better reflects these latter components that could contribute to worsening right heart failure. Several studies have begun to measure and explore the clinical relevance of PA stiffness in PH. 
PA stiffness is an important factor governing dynamic afterload. It has also been reported that proximal PA stiffness may increase early in the course of $\mathrm{PH}$, suggesting a potential contributory role of PA stiffness in the development and progression of $\mathrm{PH}$. The association between vascular stiffening and disease severity is believed to be due to several factors: a) stiffening reduces the windkessel effect of the elastic arteries, leading to greater flow inefficiency; b) stiffening increases RV afterload independent of pulmonary vascular resistance (PVR); and c) changes in the flow and pressure waveforms due to stiffening of the pulmonary circulation have been shown to stimulate cellular signaling pathways in distal vessels and the lungs that aggravate the existent vascular disease. Increased stiffness observed in PA hypertension may be secondary to elevated distending pressures or/and to structural changes of the PA wall. IVUS has been used for quantifying the pulsatility of PA (IVUSp) in IPAH (Berger et al., 2002; Rodés-Cabau et al., 2003). The arterial pulsatility depends on intraluminal pressure and on viscoelastic properties of the arterial wall, while stiffness depends on the extent of wall remodeling. The lack of correlation between IVUSp and usual hemodynamic variables in patients with IPAH suggests that wall remodeling may influence the functional properties of the arterial wall derived from IVUS. We have already experimentally demonstrated that only those indexes of wall stiffness that simultaneously consider changes of pressure and diameter of PA are correlated with the incremental elastic modulus (gold standard for the elastic properties of a vessel wall) (Bia et al., 2005a). It has been reported that a decreased pulsatility of both proximal (magnetic resonance imaging) (Gan et al., 2007; Sanz, Fernández-Friera \& Moral, 2010) and distal (IVUS) (Rodés-Cabau et al., 2003) PA is related to increased long term mortality in patients with IPAH. However, because of the strong dependency of strain on underlying pressures, quantification of IVUSp alone is insufficient to fully characterize PA elastic properties, explaining the absence of its correlation with basic hemodynamic parameters (Rodés-Cabau et al., 2003; Grignola et al., 2010).

\subsection{Estimation of local pulmonary arterial pulsatility and stiffness indexes by IVUS}

We studied twenty five consecutive patients with IPAH who underwent cardiac catheterisation. Hemodynamic evaluation and IVUS imaging of the PA were performed during the same procedure according to a protocol previously reported. All patients underwent a routine right heart catheterisation and simultaneous IVUS in a supine position and breathing room air (Rodés-Cabau et al., 2003). A 7F Swan-Ganz catheter (Edwards Lifesciences, USA) was inserted into a brachial vein and a 5F end-hole catheter was inserted into the right radial artery to monitor systemic arterial pressure. Both catheters were connected to fluid-filled transducers which were positioned at the anterior axillary line level and zeroed at the atmospheric pressure. Right atrial pressure, PA pressure, pulmonary arterial occlusion pressure (PAOP) and systemic arterial pressure were measured. Cardiac output was estimated by the Fick method assuming basal oxygen consumption $\left(125 \mathrm{ml} \mathrm{O} 2 / \mathrm{min} / \mathrm{m}^{2}\right)$ (Soto \& Kleczka, 2008). Cardiac index was calculated by dividing the cardiac output by body surface area. After hemodynamic measurements were done, an Eagle Eye Gold catheter 20MHz, 3.5F (Volcano Corporation, USA) with an axial resolution of $200 \mu \mathrm{m}$ and a pullback of $0.5 \mathrm{~mm} / \mathrm{s}$, was advanced over a 0.014 " guidewire into the same PA branch using an exchange guidewire system and X-ray control (Fig. 1). This method guarantees that IVUS images and PA pressure are obtained from the same arterial segment in the pulmonary arterial tree. The images were obtained from the segmental PA of the inferior lobes (elastic PA between 2-4 mm) (Bressollette et al., 2001) and stored in digital 
format. The images were independently analyzed off-line by two observers blinded for clinical and hemodynamic findings (E.D., M.V.). The end-diastolic (minimal) and endsystolic (maximal) cross-sectional areas of the distal segment were measured (Fig. 2). Pulmonary vascular disease is diffuse but not uniform in the pulmonary tree. However, considering that Bresollette et al. have shown that structural abnormalities were significantly more severe in the lower lobes, it is possible that the pulmonary vascular disease process associated with $\mathrm{PH}$ begins in this region because of the higher hydrostatic pressure (Bresollette et al., 2001).

Steady (PVR) and pulsatile (pulmonary arterial capacitance, $\mathrm{Cp}$ ) components of afterload were estimated. PVR and Cp were calculated as (mean PA pressure-PAOP)/cardiac output and the ratio between the stroke volume and the PA pulse pressure (SV/Pp), respectively. IVUSp was estimated as: ((systolic area-diastolic area)/diastolic area) $) \times 100 ;((\mathrm{sA}-\mathrm{dA}) / \mathrm{dA}) \times$ 100 (Fig. 2).

PA stiffness indexes were assessed by arterial cross-sectional area and local Pp (RodésCabau et al., 2003; Laurent et al., 2007; Grignola et al., 2010):

$$
\begin{gathered}
\text { Elastic modulus }\left(\mathrm{E}_{\mathrm{P}}\right): \mathrm{dA} \times \mathrm{Pp} /(\mathrm{sA}-\mathrm{dA}) \\
\text { Cross-sectional distensibility }\left(\mathrm{D}_{\mathrm{CS}}\right): \text { IVUSp } \times \mathrm{Pp} \\
\text { Local compliance }\left(\mathrm{C}_{\mathrm{L}}\right):(\mathrm{sA}-\mathrm{dA}) / \mathrm{Pp}
\end{gathered}
$$
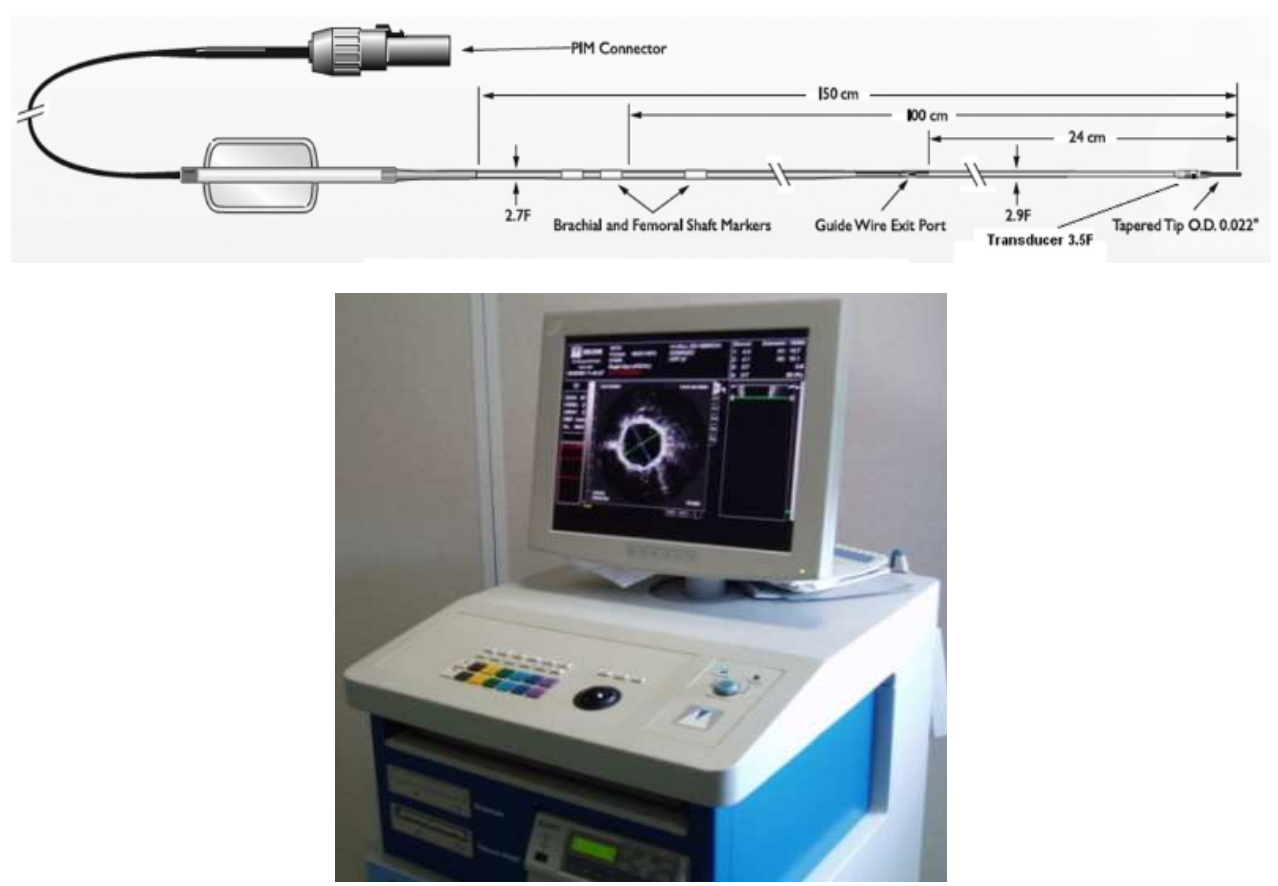

Fig. 1. Eagle Eye Gold imaging catheter (20 MHz) and console (Volcano Corporation). 


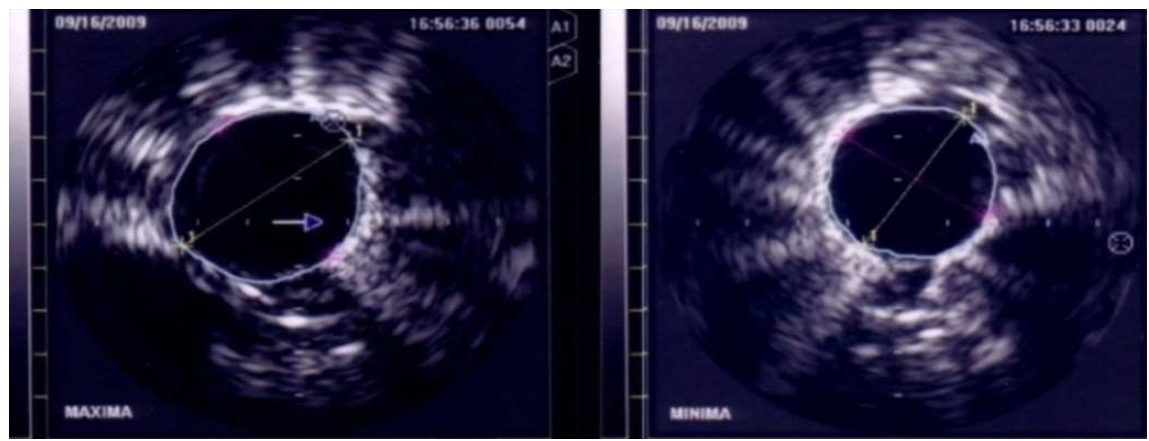

Fig. 2. Representative IVUS images of a patient with IPAH. Left side: systolic phase and right side: diastolic phase of the cardiac cycle. (IVUSp $=11.8-9.4 / 9.4=25.5 \%$ ).

Figure 3 shows mean values of IVUSp and $E_{P}$ in four groups of patients studied at our institution: ten control patients (with suspicion of PAH); a recent group of eighteen IPAH patients (2008-2009) split into two groups according to the median of $\mathrm{E}_{\mathrm{P}}$ (group $1 \leq 190$ $\mathrm{mmHg}$ and group $2>190 \mathrm{mmHg}$ ) and a historical group of more severe IPAH patients (prior to 2003) (Rodés-Cabau et al., 2003; Domingo et al., 2011).

It can be seen that control group patients have a significantly lower $\mathrm{E}_{\mathrm{P}}$ and higher IVUSp than IPAH patients. In according with our results, Berger et al. showed that arterial wall distensibility (the inverse of $\mathrm{E}_{\mathrm{P}}$ ) significantly decreased in children with advanced pulmonary vascular disease in comparison with normal subjects, corresponding with an average $E_{P}$ of 182 $\mathrm{mmHg}$ versus $50 \mathrm{mmHg}$ (Berger et al., 2001). However, they did not find differences in vascular pulsatility between patients with pulmonary vascular disease and control subjects.

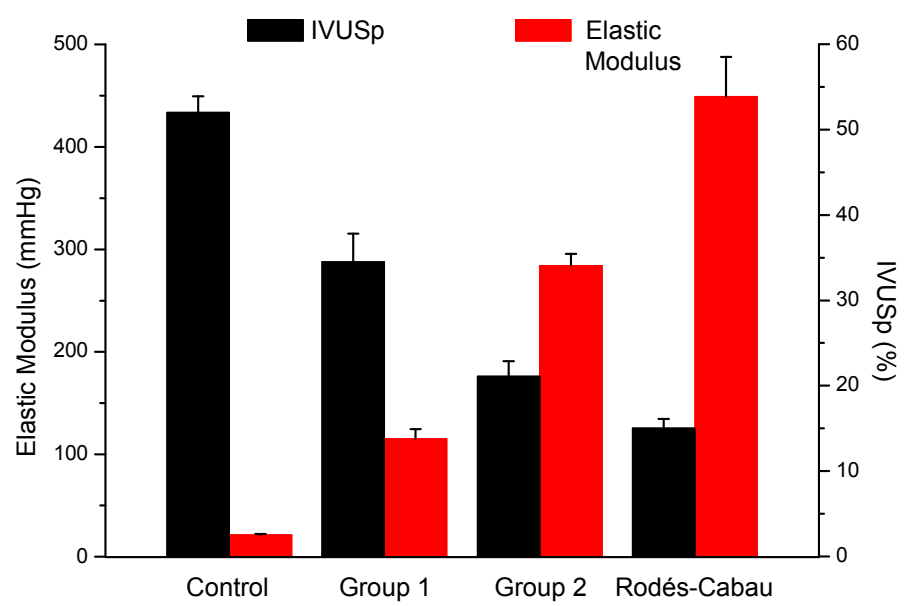

Fig. 3. Bar diagram showing the mean \pm ES of elastic modulus and pulsatility (IVUSp) of control $(\mathrm{n}=10)$ and IPAH patients (Group 1, n=9; Group 2, n=10 and Rodés-Cabau, $n=20)$. 
We suggest that IVUSp and $E_{P}$ are different qualitative indexes of the arterial wall viscoelastic properties. IVUSp is a normalized cross-sectional pulsatility that depends only on arterial cross-sectional signals (geometric related index) and $E_{\mathrm{P}}$ is a local PA stiffness index normalized by Pp.

We have previously shown that PA arterial wall indexes that depend only on arterial geometric signals (such as normalized cross-sectional pulsatility) do not follow the same patterns as the incremental elastic modulus ( $E_{I N C}$, gold standard of the elastic properties of a vessel wall) (Bia et al., 2005a). Only during vascular smooth muscle activation did arterial cross-sectional area and wall viscosity increase with regard to the passive situation and independent from the pulse pressure level, suggesting that absolute or normalized pulse cross-sectional area could be an indirect or qualitative marker of arterial wall viscosity status. In relation to this, the absence of a relation between IVUSp and hemodynamic variables suggests that changes in pulmonary vessel structure are responsible for functional alteration shown by ultrasound (Rodés-Cabau et al., 2003).

The incremental elastic modulus is commonly used in elasticity theory because it best defines the intrinsic properties (independently of size or geometry) of a given material (eg, the arterial wall). Consequently, it is considered the "gold standard" for the evaluation of the elastic response of a material. The requirement for the geometric characteristics of the arterial segment (thickness and diameter of the arterial wall) to be known makes this a difficult modulus to calculate in a clinical setting. The $E_{P}$ allows calculation of the arterial rigidity in relation to the unit strain, and as such, is independent of the diameter or crosssectional area. Its particular clinical usefulness comes from the fact that it is only necessary to know the maximum systolic and minimum diastolic values of the arterial pressure and cross-sectional signals in order to perform the calculation. However, since the calculation requires the use of the maximum and minimum values for pressure and cross-sectional in order to calculate the secant between these points, its values include both the elastic and viscous behavior of the arterial wall. Thus, due to the viscoelastic characteristic of the arterial wall, the maximum systolic diameter of the artery reached during arterial distension is highly dependent upon the level of arterial viscosity (Bia et al., 2005b).

Therefore, we can state that IVUSp is very dependent on wall viscosity and that $E_{P}$ depends on the mechanical effect of PA pressure, the vascular smooth muscle tone variations, and the changes in the PA wall structure. So, as might be expected, control patients have the higher wall PA buffering function (higher IVUSp plus the lower $E_{P}$ ), and the group studied by Rodés-Cabau showed the worst PA buffering function (Fig. 3).

\subsection{Correlation of local pulmonary arterial stiffness indexes with steady and pulsatile afterload}

The arterial hydraulic load can be described completely by the so-called pulmonary arterial input impedance that accounts for the relationship between pulsatile pressure and flow. However, this description is not only difficult to derive but also complex to interpret (Nichols \& O'Rourke, 2005). Therefore, several simplified descriptions of the arterial circulation have been proposed. One such description is the two-element Windkessel model which consists of physiologically easily interpretable parameters and describes the hemodynamics in terms of resistance and compliance. The resistance of the model is the 
PVR. PVR is mainly located in the small arteries and arterioles, since resistance strongly depends on vessel diameter. The compliance of the model $(\mathrm{Cp})$ is the storage capacity of all arteries and arterioles taken together. $\mathrm{Cp}$ is related to arterial wall elasticity and vessel size (i.e. radius and wall thickness). The compliance of the arterial tree allows the arteries to expand passively during systole and to recoil during diastole. This has two important effects: a) the compliant arteries are able to store the ejected blood-volume in systole and release this volume during diastole resulting in constant peripheral blood flow throughout the entire cardiac cycle and, b) the compliant arteries dampen/cushion the pressure so that pressure variations in the PA are smaller than in the ventricle. If we assume that the periphery is closed for a moment, the increase in pressure $(\Delta \mathrm{P}=\mathrm{Pp})$ resulting from a single stroke volume (SV) relates thus to compliance: $\mathrm{Cp}=\mathrm{SV} / \mathrm{Pp}$, which overestimates the real compliance. Calculation of $\mathrm{Cp}$ is, in practice, more difficult because there is blood leaving the arterial system through the periphery (microcirculation) while cardiac ejection takes place. Although the pulse pressure method was shown to result in reliable data, the SV/Pp ratio is an acceptable method to derive compliance in vivo (Chemla et al., 1998; Stergiopulos, Segers \& Westerhof, 1999).

Clinicians usually define RV afterload in terms of PVR and this measure is often used as a primary or secondary end-point in clinical studies. However, PVR only reflects the nonpulsatile (steady) component of blood flow, and neglects the important contribution of compliance. In recent years it has become clear that in PH not only the contribution of PVR is of importance but that the decrease in $\mathrm{Cp}$ plays an equally important role. $\mathrm{Cp}$ takes into account the pulsatile components of the arterial load and, therefore, is an important factor contributing to systolic and diastolic pressure. Besides, it was shown to be a prognosis factor for mortality (Mahapatra et al., 2006). It is noteworthy that the common PA and proximal left and right arteries together contribute only $15-20 \%$ of total $\mathrm{Cp}$, suggesting that arterial compliance is distributed over the entire pulmonary arterial bed, like PVR (Saouti et al., 2010). On the contrary, in the systemic arterial tree the compliance is mainly located in the aorta ( $80 \%$ of total compliance in thoracic-abdominal aorta), and resistance is mainly located in arterioles. This distribution depends on the number of peripheral vessels, which is $\approx 8-10$ times more in the pulmonary system than in the systemic tree (Saouti et al., 2010).

Cp quantifies total (rather than local) arterial compliance, given an average of what is happening in the whole arterial pulmonary tree without allowing the analysis of regional changes and to detect early-stage wall remodeling. As we previously mentioned, the simultaneous use of IVUS and conventional RHC allowed us to estimate local viscoelastic properties of the PA as a whole. A major advantage is that local arterial stiffness is directly determined from the change in pressure driving the change in volume, i.e. without using any model of the circulation. Both the change in pressure and size should be obtained from the same arterial segment. It has also been reported that proximal PA stiffness may increase early in the course of IPAH, suggesting a potential contributory role of PA stiffness in the development and progression of PAH (Sanz et al., 2009).

In spite of IPAH patients with higher wall stiffness (group 2 and Rodés-Cabau group) showing lower IVUSp are associated with decreased Cp and increased PVR, neither Cp nor PVR correlated with IVUSp (Fig. 4). On the contrary, the three local PA stiffness indexes (normalized by pulse pressure) correlated significantly with global capacitance and resistance properties of the pulmonary arterial tree (Fig. 5) (Grignola et al., 2010). 
As mentioned before, the assessment of PA stiffness indexes requires the use of the maximum and minimum values for pressure and cross-sectional area including both the elastic and viscous behavior of the PA arterial wall.
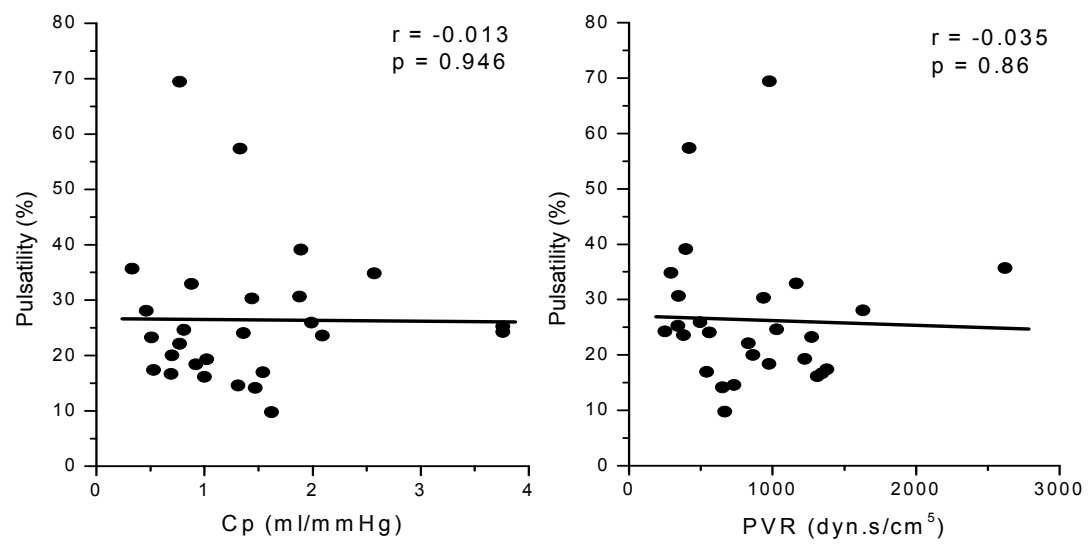

Fig. 4. Absence of correlation between pulsatility (IVUSp) and pulsatile (Cp, capacitance index) and steady (PVR, pulmonary vascular resistance) pulmonary afterload components.
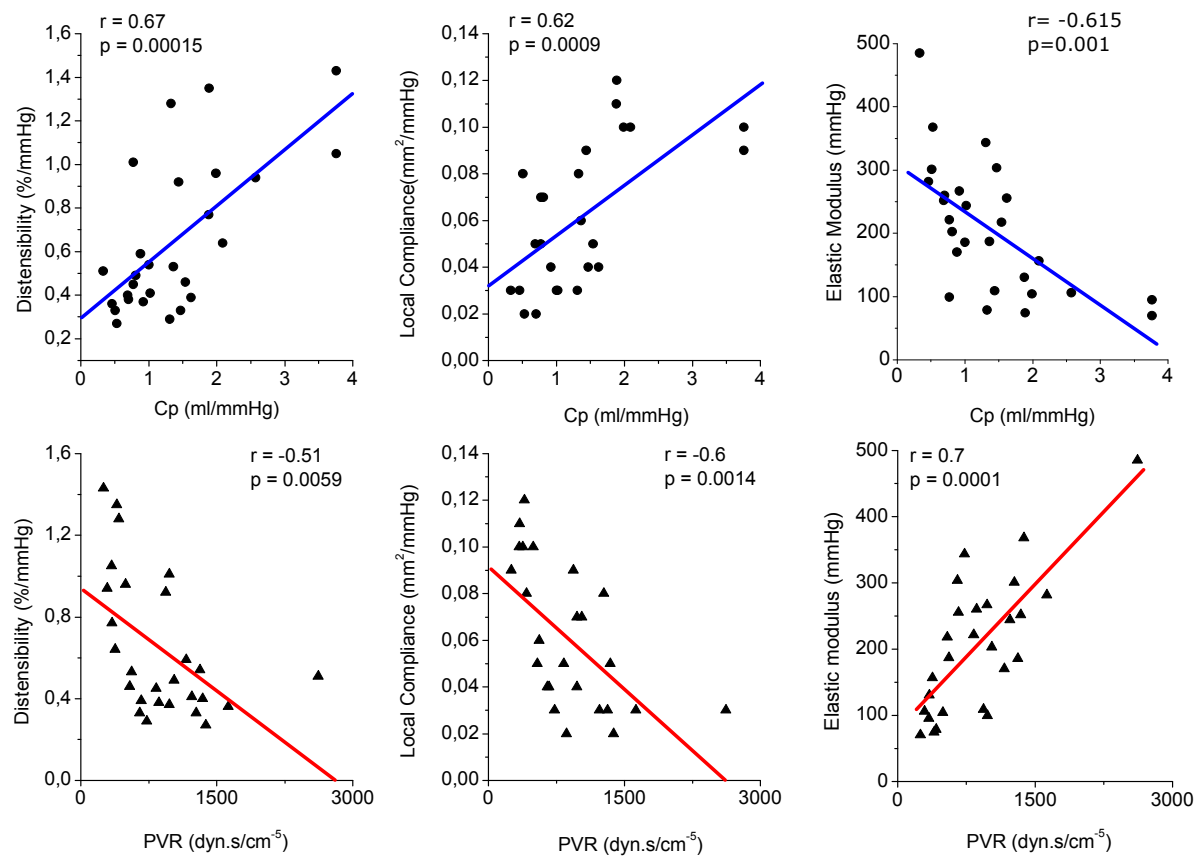

Fig. 5. Correlations between local PA stiffness indexes normalized by pulse pressure and pulsatile (Cp, capacitance index) and steady (PVR, pulmonary vascular resistance) pulmonary afterload $(\mathrm{n}=25)$. 
By contrast, IVUSp is only an indirect marker of arterial wall viscosity status, explaining the absence of correlation between IVUSp and afterload parameters.

Recent studies showed that PVR and $\mathrm{Cp}$ are inversely related by a hyperbola, and in combination describe the RV afterload better than either PVR or Cp separately (Lankhaar et al., 2006, 2008). In other words, the product i.e. the RC-time, in the pulmonary circulation remains the same in healthy subjects and in patients with IPAH and chronic thromboembolic pulmonary hypertension, and even after treatment (Saouti et al., 2010).

Figure 6 shows that in the early stage of PAH a small increase in PVR will be accompanied by a relatively large drop in $\mathrm{Cp}$ (patient $\mathrm{A}$ ). However, in later stages when the vascular disease progresses, the increase in PVR will continue but the drop in Cp will be limited as the vascular wall stiffness will reach a maximum (patient $B$ ).

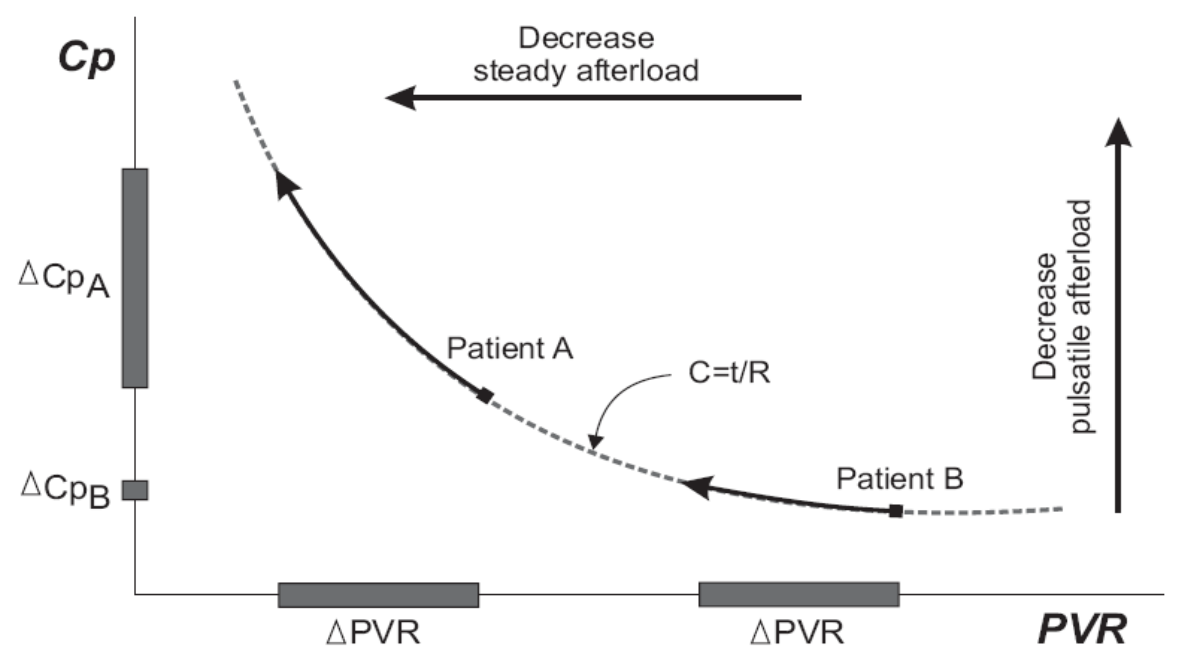

Fig. 6. Inverse hyperbolic relationship between pulmonary arterial compliance $(\mathrm{Cp})$ and pulmonary vascular resistance (PVR). $\Delta$ : change.

Finally, compliance in the pulmonary arterial system is distributed over the entire arterial system and stands at the basis of the constancy of the RC time. Applying this RC approach, we can see that patients with an $E_{P}$ lower than the median (group 1, $E_{P}<190 \mathrm{mmHg}$ ) are distributed in the upper left of the hyperbola and that patients of group 2 ( $E_{P} \geq 190 \mathrm{mmHg}$ ) hold the bottom right of the RC curve (Fig. 7A). On the contrary, splitting the patients according to the median of the IVUSp $(23 \%)$ does not reveal any specific distribution along the RC curve (Fig. 7B). We can affirm that patients with lesser changes in pulmonary vascular bed $\left(E_{P}<190 \mathrm{mmHg}\right)$ are characterized by the fact that a small change of PVR leads to a considerable change in $\mathrm{Cp}$ and can, therefore, be better detected by a change in compliance than a change in PVR and viceversa. 

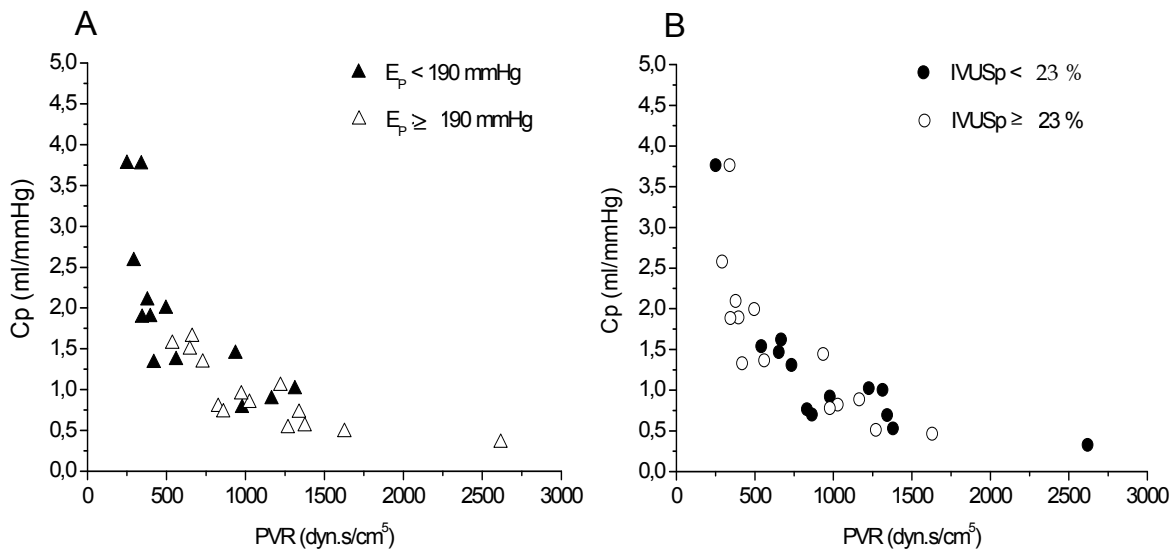

Fig. 7. RC curve of patients with IPAH. The population was split into two groups according to the median of Ep and IVUSp.

\subsection{Correlation of local pulmonary arterial elastic modulus with acute vasoreactivity}

Detection of acute pulmonary vasoreactivity is important for the evaluation of patients with PAH in different scenarios (Tonelli, Alnuaimat \& Mubarak, 2010). However, the clinical relevance of acute vasoreactivity testing in PAH for identifying patients with a marked vasoreactive component, who may thus benefit from chronic calcium channel blocker therapy, has been established only in IPAH (Ghofrani, Wilkins \& Rich, 2008). The criteria for identifying responder and non-responder patients in IPAH have been changed in the last twenty years (Tonelli, Alnuamat \& Mubarak, 2010). Nowadays, according to the retrospective study of Sitbon et al., a positive response is defined as a decrease in mean PA pressure $(\mathrm{Pm})>10 \mathrm{mmHg}$, reaching an absolute $\mathrm{Pm}<40 \mathrm{mmHg}$ with an unchanged or increased cardiac output (Sitbon et al., 2005). However, the acute response to a vasodilator agent is not an all-or-nothing phenomenon, since different degrees of vasoreactivity are present in all patients with PAH, even in those defined as non-responders by the revised current criteria (Vieira Costa et al., 2005). Pathophysiologically, the different criteria used throughout time to define a positive response may identify patients with different degrees of vascular remodeling. It has been suggested that the currently used criteria of acute responder might identify those patients with a predominant vasoconstriction, a better hemodynamic profile and less remodeling of the vascular wall (Vieira Costa et al., 2005). Recently, Jardim et al. have proposed PA distensibility $\geq 10 \%$ (magnetic resonance imaging) as a noninvasive surrogate response marker to the acute vasodilator test in patients with PAH (Jardim et al., 2007).

However, one aspect that has not been evaluated to date is the relationship between pulmonary arterial wall stiffness, real absolute vasodilatation, and vasoreactivity response (in terms of conventional vasoreactivity criteria) during the acute vasoreactivity testing. Hemodynamic evaluation and IVUS imaging of the PA were performed in the same 
procedure according to a protocol previously reported (Rodés-Cabau et al., 2003; Grignola et al., 2011). Table 1 describes the baseline clinical and hemodynamic characteristics of the 19 IPAH patients enrolled in the study.

\begin{tabular}{|l|l|}
\hline Variables & Value \\
\hline Demographic variables & \\
\hline Age, years & $52 \pm 15$ \\
\hline Gender, M / F & $6 / 13$ \\
\hline Functional status & \\
\hline NYHA class I-II / III-IV & $12 / 7$ \\
\hline 6MWD, m & $386 \pm 105$ \\
\hline Hemodynamic measurements & \\
\hline $\mathrm{CI}, \mathrm{l} / \mathrm{m} / \mathrm{m}^{2}$ & $2.4 \pm 0.8$ \\
\hline $\mathrm{SVI} \mathrm{ml} / \mathrm{m}^{2}$ & $30 \pm 10$ \\
\hline $\mathrm{Pm}, \mathrm{mmHg}$ & $47 \pm 18$ \\
\hline $\mathrm{Pp}, \mathrm{mmHg}$ & $47 \pm 20$ \\
\hline $\mathrm{RAP}, \mathrm{mmHg}$ & $8.2 \pm 4.8$ \\
\hline $\mathrm{PVRi}, \mathrm{WU} \cdot \mathrm{m}^{2}$ & $21 \pm 12$ \\
\hline $\mathrm{PAOP}, \mathrm{mmHg}$ & $10 \pm 3$ \\
\hline $\mathrm{SvO}{ }_{2} \%$ & $64 \pm 7$ \\
\hline
\end{tabular}

Table 1. Clinical and hemodynamic data of the patients with IPAH $(n=19)$. (CI: cardiac index; PAOP: pulmonary arterial occlusion pressure; Pm and Pp: mean and pulse arterial pulmonary pressures; PVRi: pulmonary vascular resistance index; RAP: mean right atrial pressure; SVI: stroke volume index; $\mathrm{SvO}_{2}$ : mixed venous oxygen saturation; 6MWD: sixminute walking distance).

Acute vasoreactivity testing was performed after baseline measurements, using intravenous epoprostenol. The infusion of epoprostenol was started at a dose of $2 \mathrm{ng} / \mathrm{kg} / \mathrm{min}$, and increased progressively ( $2 \mathrm{ng} / \mathrm{kg} / \mathrm{min}$ every 10 to $15 \mathrm{~min}$ ) until a positive response was obtained or until side effects occurred (Grignola et al., 2011). Both the pressure and crosssectional area changes of PA were obtained during two stable hemodynamic states: baseline and epoprostenol infusion. The population was split into two groups according to the presence of real absolute vasodilatation (delta $\mathrm{dA} \geq 10 \%$ ) (Jardim et al, 2007). The mean dose of epoprostenol was similar in both groups $(11 \pm 2 \mathrm{ng} / \mathrm{kg} / \mathrm{min}$ in the vasodilator group and $10 \pm 1.2 \mathrm{ng} / \mathrm{kg} / \mathrm{min}$ in the non-vasodilator group) (Table 2 ).

Both groups showed a significant heart rate increase and mean aortic pressure decrease $(\mathrm{p}<0.05)$. PAOP did not change during epoprostenol infusion. Among patients who showed a real vasodilatation (delta $\mathrm{dA} \geq 10 \%$ ), 5 of the 6 had an elastic modulus below the median value (190 $\mathrm{mmHg})$, and presented baseline lower elastic modulus and higher IVUSp. On the other hand, among the patients who did not present a vasodilatation, 9 of 13 had an elastic modulus above the median value. A ROC curve showed that the presence of PA stiffness below the median value was able to differentiate patients with an acute vasodilator response, with $83 \%$ sensitivity (95\% confidence interval of $54-113 \%$ ) and $70 \%$ specificity 
(95\% confidence interval of 44-94\%). The area under the ROC curve was found to be 0.81 (95\% confidence interval 0.58-1.04; $\mathrm{p}<0.05)$. We choose this cut-off value for $\mathrm{E}_{\mathrm{P}}$ since it corresponds to the maximum Youden's index $(\mathrm{J}=0.53)$. However, no significant relationship has been found between baseline PA wall stiffness and vasodilator response and the decrease in Pm and/or in PVRi during acute vasoreactivity testing.

\begin{tabular}{|l|c|c|c|c|c|c|}
\hline & \multicolumn{2}{|c|}{$\begin{array}{c}\text { All patients } \\
(\mathrm{n}=19)\end{array}$} & \multicolumn{2}{c|}{ Vasodilator group $(\mathrm{n}=6)$} & \multicolumn{2}{c|}{$\begin{array}{c}\text { Non-vasodilator group } \\
(\mathrm{n}=13)\end{array}$} \\
\hline & Basal & Epo & Basal & Epo & Basal & Epo \\
\hline $\mathrm{CI}, \mathrm{l} / \mathrm{m} / \mathrm{m}^{2}$ & $2.3 \pm 0,6$ & $2.7 \pm 1.3 \dagger$ & $2.7 \pm 1.0$ & $3.3 \pm 1.2 \dagger$ & $2.3 \pm 0.6 \ddagger$ & $2.5 \pm 0.9$ \\
\hline $\mathrm{SVI} \mathrm{ml} / \mathrm{m}^{2}$ & $30 \pm 10$ & $33 \pm 15$ & $30 \pm 14$ & $42 \pm 16 \dagger$ & $30 \pm 8 \ddagger$ & $28 \pm 7$ \\
\hline $\mathrm{Pm}, \mathrm{mmHg}$ & $50 \pm 18$ & $47 \pm 18$ & $49 \pm 17$ & $48 \pm 20$ & $46 \pm 16$ & $42 \pm 14$ \\
\hline $\mathrm{Pp}, \mathrm{mmHg}$ & $50 \pm 20$ & $31 \pm 12 \dagger$ & $50 \pm 18$ & $46 \pm 20$ & $44 \pm 16$ & $41 \pm 16$ \\
\hline $\mathrm{PVRi}, \mathrm{Wu} \cdot \mathrm{m}^{2}$ & $21 \pm 12$ & $15 \pm 9 \dagger$ & $24 \pm 17$ & $17 \pm 11 \dagger$ & $19 \pm 10$ & $15 \pm 7$ \\
\hline $\mathrm{Cp}, \mathrm{ml} / \mathrm{mmHg}^{2}$ & $1.38 \pm 1$ & $2.1 \pm 1.1 \dagger$ & $1.4 \pm 0.9$ & $1.8 \pm 1.2 \dagger$ & $1.3 \pm 0.8$ & $1.4 \pm 0.7$ \\
\hline $\mathrm{IVUSp}, \%$ & $27.8 \pm 12.9$ & $23.8 \pm 10.5 \dagger$ & $35.6 \pm 17$ & $26.5 \pm 15 \dagger$ & $24.0 \pm 8.4 \ddagger$ & $22.1 \pm 6.5$ \\
\hline Ep, $\mathrm{mmHg}$ & $195 \pm 97$ & $220 \pm 124$ & $173 \pm 85$ & $244 \pm 110$ & $224 \pm 81$ & $206 \pm 87$ \\
\hline $\mathrm{dArea}, \mathrm{mm}{ }^{2}$ & $11.7 \pm 7.6$ & $10.3 \pm 7.2$ & $11.3 \pm 10.8$ & $12.4 \pm 11.6$ & $12.0 \pm 6.0$ & $9.1 \pm 2.6$ \\
\hline sArea, $\mathrm{mm}{ }^{2}$ & $15.1 \pm 10$ & $12.7 \pm 9$ & $15.2 \pm 14.5$ & $15.5 \pm 14.5$ & $15.0 \pm 8.0$ & $11.0 \pm 3.4$ \\
\hline$\Delta$ Area, $\mathrm{mm}^{2}$ & $3.3 \pm 2.7$ & $2.3 \pm 2.1 \dagger$ & $4.0 \pm 3.9$ & $3.3 \pm 3.3$ & $3.0 \pm 2.1$ & $1.9 \pm 1.1$ \\
\hline
\end{tabular}

Table 2. Hemodynamic and IVUS data before (baseline) and after acute vasoreactivity testing (Epo) of both groups. (CI: cardiac index; Cp: pulmonary capacitance index; dArea and sArea: diastolic and systolic lumen area; $\mathrm{E}_{\mathrm{P}}$ : elastic modulus; IVUSp: pulmonary arterial pulsatility; Pm and Pp: mean and pulse arterial pulmonary pressures; PVRi: pulmonary vascular resistance index; SVI: stroke volume index. $\uparrow \mathrm{p}<0.05$ Basal vs. Epo; $\ddagger \mathrm{p}<0.05$ between basal conditions of two groups).

The similar baseline Pm and Pp between both groups allows to state that the acute real vasodilator response is the direct consequence of better preserved viscoelastic wall properties of PAs. No significant relationship has been found between PA wall stiffness and vasodilator response and the decrease in Pm and/or in PVRi during acute vasoreactivity testing. This is not consistent with the hypothesis that a favorable vasoreactive response is related to a less advanced stage of the pulmonary vascular disease (Raffy et al., 1996). Therefore, the acute vasodilatation responder patient may not always be the acute vasoreactive responder patient (current criteria).

The analysis of IVUSp and $E_{P}$ during the acute vasoreactivity testing showed that the patients with a vasodilator response had an isobaric (similar Pm) worsening of IVUSp $(p<0.05)$ and of $\mathrm{E}_{\mathrm{P}}(p=0.08)$. This is in agreement with Cholley et al. who reported that the isobaric relaxation of vascular wall smooth muscle produces a paradoxical increase in aortic stiffness with a concomitant increase in the incremental elastic modulus (Cholley et al., 2001). In other words, PA vasodilation by itself may cause the vessel to become stiffer since it is operating at a higher internal diameter. This fact would cause a redistribution of parietal stress into the different components of the PA wall, recruiting collagen fibers with 
higher stiffness, lower viscosity and lower wall buffering function, producing deterioration of IVUSp and $E_{P}$. This paradoxical response may also explain the lack of correlation between baseline $E_{P}$ and hemodynamic vasoreactivity during epoprostenol infusion.

In our cohort, the patients who showed a real absolute pulmonary artery vasodilation during acute vasoreactivity testing, had an isobaric response (absence of changes in Pm) with a concomitant stroke volume index increase $(40 \%)$, Cp increase $(29 \%)$ and PVRi decrease $(30 \%)$. The patients with a positive vasoreactive response according to current criteria do not necessarily have a real absolute vasodilatation on IVUS (Grignola et al., 2011). As proposed by Raffy et al., acute positive vasoreactive response to epoprostenol could be used identify a particular subgroup in the IPAH population that is characterized by a spontaneously slower evolution and hence a better prognosis (Raffy et al., 1996). The absence of IVUSp and $E_{P}$ worsening during short-term response to epoprostenol in the non-vasodilator and higher remodeling group of IPAH patients could support the greater benefit of epoprostenol in patients with worse functional class. Future studies should analyse whether absolute vasodilatation during acute vasodilator challenge is the most useful criterion to determine responders to calcium channel blocking therapy. We firmly believe that the study of local stiffness indexes of distal PA in IPAH may be useful for analyzing direct and long term effects of specific drugs designed for IPAH treatment on the remodeling process of the pulmonary arterial vascular tree (Rich, 2009; Rich et al., 2010).

\section{Optical Coherence Tomography (OCT): A structural approach for the evaluation of pulmonary arterial wall in PAH}

Optical Coherence Tomography (OCT) has emerged in recent years as one of the most promising intravascular imaging modalities, capable of providing cross-sectional images of tissue with a homoaxial resolution of $10 \mu \mathrm{m}$ and a lateral resolution of $20 \mu \mathrm{m}$, which is $\approx 10$ times higher than that of any available imaging modality (Table 3).

The principle of OCT is analogous to pulse-echo ultrasound imaging: however, light is used rather than sound to create the image. Whereas US produces images from the backscattered sound "echoes", OCT uses infrared light waves that reflected off the internal microstructure within the biological tissues due to their differing optical indices. The use of light provides significantly higher spatial resolution than that of any ultrasound technique. However, this is at the expense of a reduced penetration depth and the need to create a blood-free environment for imaging. In small arteries (diameter lesser than 2-3 mm), blood (namely red blood cells) represents a non-transparent tissue causing multiple scattering and substantial signal attenuation. As a consequence, blood must be displaced during OCT imaging, with the need for balloon occlusion and intra-arterial flush (Pratty et al., 2010).

OCT utilizes a near-infrared light emitted by a super-luminescent diode in combination with advanced fibre-optics to create a dataset of the artery studied. Both the bandwidth of the infrared light used and the wave velocity are orders of magnitude higher than in medical ultrasound. The resulting resolution depends primarily on the ratio of these parameters, and is one order of magnitude larger than that of IVUS (Table 3). 


\begin{tabular}{|l|l|l|}
\hline & TD-OCT & IVUS \\
\hline Energy source & Near-infrared light & Ultrasound (20-45 MHz) \\
\hline Wave-length, $\mu \mathrm{m}$ & 1.3 & $35-80$ \\
\hline Resolution, $\mu$ & $15-20$ (axial); 20-40 (lateral) & $100-200$ (axial); 200-300 (lateral) \\
\hline Probe size $(\mu)$ & 400 & 1100 \\
\hline Frame rate, frames/s & $15-20$ & 30 \\
\hline Tissue penetration, $\mathrm{mm}$ & $1-2.5$ & 10 \\
\hline Pull-back rate, $\mathrm{mm} / \mathrm{s}$ & $1-3$ & $0.5-1$, up to 40 \\
\hline Max scan diameter, $\mathrm{mm}$ & 7 & 15 \\
\hline
\end{tabular}

Table 3. Physical characteristics of time-domain optical coherence tomography vs. IVUS.

Analogous to ultrasound imaging, the echo time delay of the emitted light is used to generate spatial image information and the intensity of the received (reflected or scattered) light is translated into a (false) colour scale. As the speed of light is much faster than that of sound, an interferometer is required to measure the backscattered light (Regar et al., 2003; Farooq et al., 2009; Pratty et al., 2010). OCT produces accurate images of the arterial lumen and the lumen-vessel wall interface. Normal arteries show a clear demarcation between tunica intima (highly reflective), tunica media (poorly reflective) and tunica adventitia (highly reflective) by OCT (Regar et al., 2003) (Fig. 8). Lipid and necrotic tissue are visualized as poorly reflective structures, while fibrous tissue shows a highly reflective, uniform pattern within the artery wall.
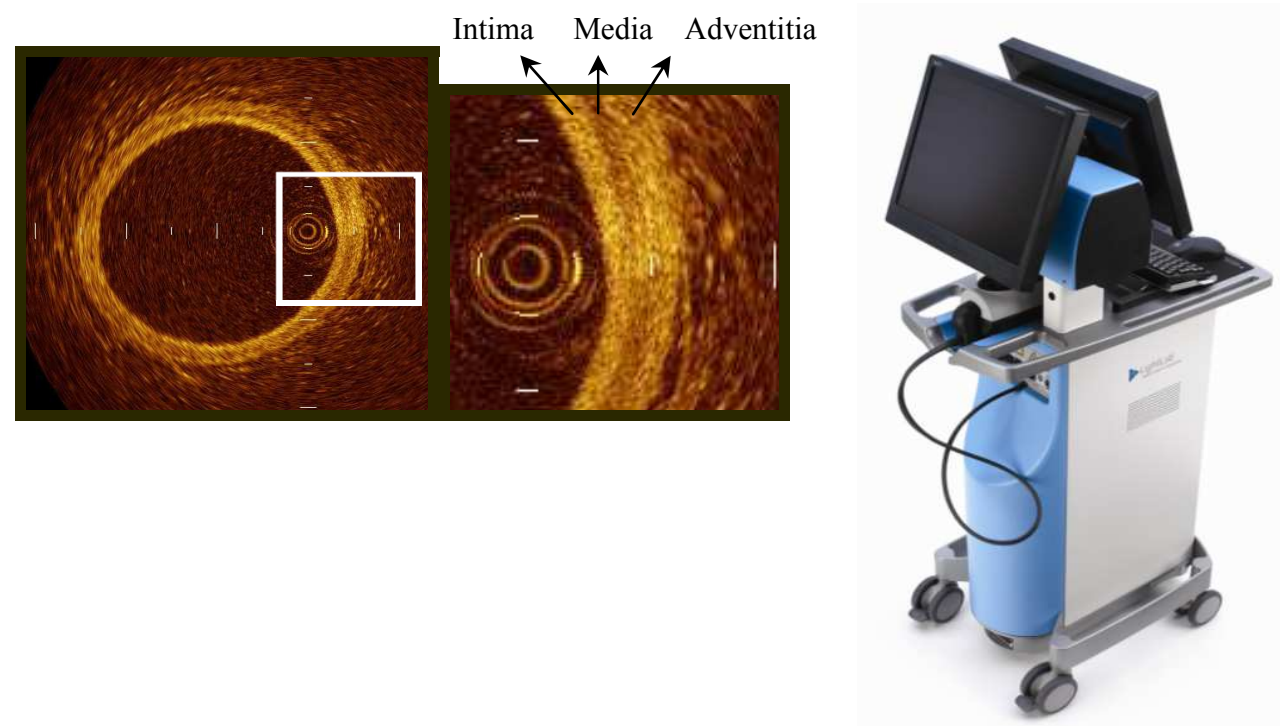

Fig. 8. Left and middle: in vivo OCT image of a normal artery with the different layers. Right: Time-Domain OCT system (Lightlab Imaging, Westford, MA, USA). 
Second-generation OCT systems have now been developed that potentially overcome many of the practical limitations of the TD-OCT scanners. This technology utilizes a detection method termed Fourier or frequency-domain detection, which allows high-speed data acquisition and real-time imaging. Using guide catheter flush without balloon occlusion, imaging at $\geq 100$ frames per second with a pull-back rate of up to $20 \mathrm{~mm} / \mathrm{second}$ has been achieved, in contrast to 5.6 frames/second for the TD-OCT system. This development has led to faster image acquisition speeds, with greater penetration depth and without loss of vital detail or resolution, and represents a great advance on current conventional OCT systems (Raffel et al., 2008; Gonzalo et al., 2010).

\subsection{Estimation of local pulmonary fibrosis by OCT}

Although the focus in understanding the mechanism of PAH has been on the small PA (< $500 \mu$ ), there is evidence that changes in impedance, resulting from stiffening of the more proximal conduit PAs, may also be a critical determinant not only of the pressure but of the ability of the right ventricle to function (Rabinovitch, 2008).

In Heath and Edwards' histopathological classification, structural changes in the PAs include the progressive intimal fibrosis from the smaller muscular PA to the medium-sized PA (Heath \& Edwards, 1958). In spite of similar clinical and hemodynamic profiles, patients differed considerably with respect to the nature of their pulmonary vascular obstructive lesions. Palevsky et al showed that an intimal area of more than $18 \%$ of the vascular crosssectional area had an $85 \%$ predictive value for identifying patients with a poor outcome during 36 months of follow-up (Palevsky et al., 1989). Therefore, accurate detection and quantification of intimal fibrosis would be important in the assessment of PA remodeling, irreversibility and prognosis of the disease. Besides, it has recently been shown that collagen content is important in extralobar PA stiffening caused by chronic hypoxia (Ooi et al., 2010). Finally, there is evidence that conduit PA stiffness is a strong predictor of mortality in PAH (Mahapatra et al., 2006; Gan et al., 2007).

According to our knowledge, there is scarce and poorly analyzed literature on the use of OCT in PAH. Tatebe et al reported the potential usefulness of OCT as a novel diagnostic tool for the differential diagnosis of distal type chronic thromboembolic $\mathrm{PH}$ from $\mathrm{PAH}$ (Tatebe et al., 2010). They showed that PA $>1 \mathrm{~mm}$ in diameter had no obstruction in the control of PAH subjects, although the media of the arteries appeared to be thickened in PAH subjects compared with controls. Finally, Hou et al. reported the OCT findings of one case of severe IPAH (Hou et al., 2010). They showed that the intima was more than twice the thickness in this patient with $\mathrm{PH}$ compared with a patient with normal PA pressure.

We quantified the relative PA wall fibrosis (\%Fib) by OCT in patients with stable IPAH (Domingo et al., 2010). After hemodynamic and IVUS measurements, a Helios coaxial occlusion balloon catheter (LightLab Imaging Inc, Westford MA, USA) was advanced over a 0,014 " guidewire into the same pulmonary artery branch, using an exchange guidewire system and X-ray control. This method guarantees that IVUS, OCT and PA pressure are obtained at the same level of the studied PA branch. The Helios is situated in the distal part of the vessel. The guidewire is replaced by an ImageWire 2000 OCT imaging catheter (LightLab Imaging Inc, Westford MA, USA). While maintaining the ImageWire in its place, the balloon is retracted to the proximal part of the branch. To prevent blood from entering 
the region of interest, the balloon is inflated to $0.6 \mathrm{~atm}$. Total occlusion is verified angiographically with a contrast injection. When occlusion is achieved, a manual continuous flush with saline is initiated for blood clearing. According to the study from Yabushita et al., fibrosis is represented by OCT as intimal thickening with a bright and homogeneous signal (Yabushita et al., 2002). In the same image the inner lumen area and the area limited by the outer boundary of fibrosis are measured. Subtraction of these two areas represents fibrosis area. Percentage of fibrosis is calculated as the ratio between the fibrosis/lumen crosssectional areas $(\% \mathrm{Fib})$ :

$$
\% \mathrm{Fib}=(\text { area of Fib/PA cross sectional area }) \times 100
$$

A typical OCT image of a distal PA in a patient with IPAH is shown in Fig. 9. External and internal markers outline the area of fibrosis and the ratio between the fibrosis area and the external cross-sectional area estimates the percentage of wall fibrosis.

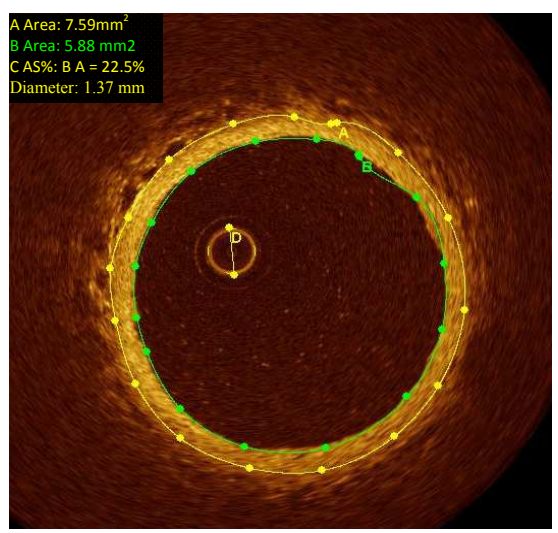

Fig. 9. In vivo OCT image of a distal pulmonary artery in a patient with IPAH. Calculation of the fibrosis of the arterial wall.

The mean OCT \%Fib was $23 \pm 7$, with an IVUSp of $33 \pm 21 \%$ and an $\mathrm{E}_{\mathrm{P}}$ of $185 \pm 107 \mathrm{mmHg}$.

\subsection{Correlation of local pulmonary fibrosis with steady and pulsatile afterload}

Histopathology of PAH is founded on structural modifications of the vascular wall of small PA characterized by thickening of all its layers. These changes include vascular wall proliferation, fibrosis and vessel obstruction (Sakao, Tatsumi \& Voekel, 2010).

In a model of chronic hypoxia $\mathrm{PH}$, pulmonary vascular remodeling increases conduit PA stiffness. Vascular collagen accumulation is a major cause of extralobar PA stiffening in hypoxia $\mathrm{PH}$. On the contrary, no significant change in elastin wall content has been observed (Ooi et al., 2010). In accordance with this, we found higher OCT \%Fib in PA (1.5 to $2 \mathrm{~mm}$ of diameter) of patients with IPAH with respect to control patients (23 \pm 7 vs. $1.4 \pm$ $1.3 \%$ ). Patients with a higher wall fibrosis showed higher steady (PVR increase) and pulsatile (Cp decrease) components of PA afterload. OCT \%Fib was better correlated with 
capacitance $(\mathrm{r}=-0.47 ; \mathrm{p}=0.04)$, than with PVR $(\mathrm{r}=0.44 ; \mathrm{p}=0.06)$ (Domingo et al., 2010). Although wall fibrosis is associated with an increase in $E_{\mathrm{P}}$, the absence of correlation between structural (OCT fibrosis) and functional (IVUSp; $\mathrm{E}_{\mathrm{P}}$ ) wall remodeling, reveals the complex interaction between the different PA wall components in the remodeling process. The increased $E_{P}$ not only depends on the extent of wall fibrosis. Vasoconstriction, change in elastin wall content, transmural PA pressure and wall geometrical factors (thickness/radius ratio) also influence $E_{P}$. Neither IVUS \%Fib nor pulsatility was correlated with PA afterload.

\section{Conclusion}

$\mathrm{PAH}$ is a rare and severe condition characterized by vascular proliferation and remodeling of the small PA wall, resulting in a progressive increase in pulmonary vascular impedance and ultimately right ventricular failure and death. Both PA elastic modulus assessed by IVUS and wall percentage of fibrosis assessed by OCT correlated with the severity of PA dynamic afterload (global capacitance and resistance properties of the pulmonary arterial tree). Patients with a higher degree of remodeling had a worse clinical and hemodynamic profile. The severity of remodeling of elastic distal PA did not correlate with the acute response of mean PA pressure and/or PVRi to epoprostenol during the acute vasoreactivity test.

We suggest the potential usefulness of IVUS and OCT as novel diagnostic tools for evaluation of PA wall functional and structural remodeling in patients with PAH group I, during acute vasoreactivity testing, along the disease process, and as a marker of treatment response, complementary to clinical and hemodynamic evaluation. It is possible that the current criteria for an acute positive pulmonary vasoreactivity test (decrease in $\mathrm{Pm}>10 \mathrm{mmHg}$, reaching an absolute $\mathrm{Pm}<40 \mathrm{mmHg}$ with an unchanged or increased cardiac output) would not necessarily identify patients with lower vascular remodeling. This fact would explain the long-term clinical benefit of calcium blockers in only $50 \%$ of patients considered hemodynamic responders in the acute vasoreactivity testing.

\section{Acknowledgements}

To Manuel Vázquez (RN) for his technical assistance. This work was partially supported by a financial grant from Glaxo Smith Kline. Juan C Grignola is supported by CSIC (Comisión Sectorial de Investigación Científica) and ANII (Agencia Nacional de Investigación e Innovación).

\section{References}

Berger, R.M.F., Cromme-Dijkhuis, A.H., Hop, W.C.J., Kruit, M.N. \& Hess, J. (2002). Pulmonary arterial wall distensibility assessed by intravascular ultrasound in children with congenital heart disease. Chest Vol. 122, pp. 549-557, ISSN 0012-3692.

Bia, D., Armentano, R.L., Grignola, J.C., Craiem, D., Zócalo, Y., Ginés, F. \& Levenson, J. (2003). The vascular smooth muscle of great arteries: local control site of arterial buffering function? Revista Española de Cardiología Vol. 56, pp. 1202-1209, ISSN 03008932. 
Bia, D., Barra, J.G., Grignola, J.C., Ginés, F. \& Armentano, R.L. (2005a). Pulmonary artery smooth muscle activation attenuates arterial dysfunction during acute pulmonary hypertension. Journal of Applied Physiology Vol. 98, pp. 605-613, ISSN 1439-6327.

Bia, D., Aguirre, I., Zócalo, Y., Devera, L., Cabrera Fischer, E. \& Armentano, R.L. (2005b). Regional differences in viscosity, elasticity, and wall buffering function in systemic arteries: pulse wave analysis of the arterial pressure-diameter relationship. Revista Española de Cardiología Vol. 58, pp. 167-174 ISSN 0300-8932.

Bressollette, E., Dupuis, J., Bonan, R., Doucet, S., Cernacek, P. \& Tardif, J.C. (2001). Intravascular ultrasound assessment of pulmonary vascular disease in patients with pulmonary hypertension. Chest Vol. 120, pp. 809-815, ISSN 0012-3692.

Chemla, D., Hébert, J.L., Coirault, C., Zamani, K., Suard, I., Colin, P. \& Lecarpentier, Y. (1998). Total arterial compliance estimated by stroke volume-to-aortic pulse pressure ratio in humans. American Journal of Physiology Vol. 274, pp. 500-505, ISSN 0363-6143.

Cholley, B.P., Lang, R.M., Korcarz, C.E. \& Shroff, S.G. (2001). Smooth muscle relaxation and local hydraulic impedance properties of the aorta. Journal of Applied Physiology Vol. 90, pp. 2427-2438, ISSN 1439-6327.

Domingo, E., Grignola, J.C., Aguilar, R., Lopez-Messeguer, M., Vazquez, M. \& Roman, A. (2010). Pulmonary artery fibrosis by optical coherence tomography is correlated with pulmonary dynamic afterload in pulmonary arterial hypertension European Heart Journal Vol. 31(Suppl1), 750, P4459, ISSN 1520-765X.

Domingo, E., Grignola, J.C., Aguilar, R., Vázquez, M., López-Meseguer, M., Bravo, C. \& Roman, A. (2011). Correlation between local pulmonary stiffness and the acute vasoreactivity test in pulmonary arterial hypertension. American Journal of Respiratory and Critical Care Medicine Vol. 183, A5745, ISSN 1073-449X.

Farooq, U.M., Khasnis, A., Majid, A. \& Kassab, M.Y. (2009). The role of optical coherence tomography in vascular medicine. Vascular Medicine Vol. 14, pp. 63-71, ISSN 15385744 .

Galié, N., Manes, A., Negro, L., Palazzini, M., Bacchi-Reggiani, M.L. \& Branzi, A. (2009). A meta-analysis of randomized controlled trials in pulmonary arterial hypertension. European Heart Journal Vol. 30, pp. 394-403, ISSN 1520-765X.

Gan, C.T., Lankhaar, J.W., Westerhof, N., Marcus, T., Becker, A., Twisk, J.W.R., Boonstra, A., Postmus, P.E. \& Vonk-Noordegraf, A. (2007). Noninvasively assessed pulmonary artery stiffness predicts mortality in pulmonary arterial hypertension. Chest Vol. 132, pp. 1906-1912, ISSN 0012-3692.

Ghofrani, H.A., Wilkins, M.W. \& Rich, S. (2008). Uncertainties in the diagnosis and treatment of pulmonary arterial hypertension. Circulation Vol. 118, pp. 1195-1201, ISSN 0009-7322.

Gonzalo, N., Tearney, G.J., Serruys, P.W., van Soest, G., Okamura, T., García-García, H.M., van Geuns, R.J., van der Ent, M., Ligthart, J., Bouma, B.E. \& Regar, E. (2010). Second-generation optical coherence tomography in clinical practice. High-speed data acquisition is highly reproducible in patients undergoing percutaneous coronary intervention. Revista Española de Cardiología Vol. 63, pp. 893-903, ISSN 0300-8932.

Grignola, J.C., Domingo, E., Bravo, C., Aguilar, R., López-Messeguer, M., Vázquez, M. \& Roman, A. (2010). Local pulmonary artery stiffness indexes are correlated with 
steady and pulsatile components of right ventricular afterload in pulmonary arterial hypertension. Journal of the American College of Cardiology Vol. 55(Suppl1): A367, ISSN 0735-1097.

Grignola, J.C., Domingo, E., Aguilar, R., Vázquez, M., López-Messeguer, M., Bravo, C. \& Roman, A. (2011). Acute absolute vasodilatation is associated with lower vascular wall stiffness in pulmonary arterial hypertension. International Journal of Cardiology, doi:10.1016/j.ijcard.2011.07.020, ISSN 0167-5273.

Heath, D., \& Edwards, J.E. (1958). The pathology of hypertensive pulmonary disease: A description of six grades of structural changes in the pulmonary arteries with special reference to congenital cardiac septal defects. Circulation Vol. 18, pp. 533547, ISSN 0009-7322.

Hou, J., Qi, H., Zhang, M., Meng, L., Han, Z., Yu, B. \& Jang, K. (2010). Pulmonary vascular changes in pulmonary hypertension: optical coherence tomography findings. Circulation: Cardiovacular Imaging Vol. 3, pp. 344-345, ISSN 1941-9651.

Jardim, C., Rochitte, C.E., Humbert, M., Rubenfeld, G., Jasinowodolinski, D., Carvalho, C.R.R. \& Souza, R. (2007). Pulmonary artery distensibility in pulmonary arterial hypertension: an MRI pilot study. European Respiratory Journal Vol. 29, pp. 476-481, ISSN 0903-1936.

Lankhaar, J.W., Westerhof, N., Faes, T.J., Marques, K.M., Marcus, J.T., Postmus, P.E. \& Vonk-Noordegraaf, A. (2006). Quantification of right ventricular afterload in patients with and without pulmonary hypertension. American Journal of Physiology Vol. 291, pp. H1731-H1737, ISSN 0363-6143.

Lankhaar, J.W., Westerhof, N., Faes, T.J., Tji-Joong Gan, C., Marques, K.M., Boonstra, A., van den Berg, F.G., Postmus, P.E. \& Vonk-Nordegraaf, A. (2008). Pulmonary vascular resistance and compliance stay inversely related during treatment of pulmonary hypertension. European Heart Journal Vol. 29, pp. 168-1695, ISSN 1520-765X.

Laurent, S., Cockroft, J., Van Bortel, L., Boutouyrie, P., Gianattasio, C., Hayoz, D., Pannier, B., Vlachopoulos, Ch., Wilkinson, I. \& Struijker-Boudier, H. (2006). Expert consensus document of arterial stiffness: methodological issues and clinical applications. European Heart Journal Vol. 27, pp. 2588-2605, ISSN 1520-765X.

Macchia, A., Marchioli, R., Tognoni, G., Scarano, M., Marfisi, R.M., Tavazzi, L. \& Rich, S. (2010). Systematic review of trials using vasodilators in pulmonary arterial hypertension: why a new approach is needed. American Heart Journal Vol. 159, pp. 245-257, ISSN 0363-6135.

Mahapatra, S., Nishimura, R.A., Sorajja, P., Cha, S. \& McGoon, M.D. (2006). Relationship of pulmonary arterial capacitance and mortality in idiopathic pulmonary arterial hypertension. Journal of the American College of Cardiology Vol. 47, pp. 799-803, ISSN 0735-1097.

McLaughlin, V.V., Archer, S.L., Badesch, D.B., Barst, R.J., Farber, H.W., Lindner, J.R., Mathier, M.A., McGoon, M.D., Park, M.H., Rosenson, R.S., Rubin, L.J., Tapson, V.F. \& Varga, J. (2009). ACCF/AHA expert consensus document on pulmonary hypertension. Circulation Vol. 119, pp. 2250-2294, ISSN 0009-7322.

Nakamura, K., Akagi, S., Ogawa, A., Kusano, K.F., Matsubara, H., Miura, D., Fuke, S., Nishii, N., Nagasea, N., Kohno, K., Morita, H., Oto, T., Yamanaka, T., Otsuka, F., Miura, A., Yutani, Ch., Ohe, T. \& Ito, H. (2011). Pro-apoptotic effects of imatinib on PDGF-stimulated pulmonary artery smooth muscle cells from patients with 
idiopathic pulmonary arterial hypertension. International Journal of Cardiology, doi:10.1016/ j.ijcard.2011.02.024, ISSN 0167-5273.

Nichols W.W. \& O'Rourke M.F. (2005). McDonald's Blood Flow in Arteries: Theoretical Experimental and Clinical Principles. ISBN 0340809418 London, UK. Hodder Arnold.

Ooi, C.Y., Wang, Z., Tabima, D.M., Eickhoff, J.C. \& Chesler, N.C. (2010). The role of collagen in extralobar pulmonary artery stiffening in response to hypoxia induced pulmonary hypertension. American Journal of Physiology Vol. 299, pp. H1823-1831, ISSN 0363-6143.

Palevsky, H.I., Schloo, B.L., Pietra, G.G., Weber, K.T., Janicki, J.S., Rubin, E. \& Fishman, A.P. (1989). Primary pulmonary hypertension: Vascular structure, morphometry and responsiveness to vasodilator agents. Circulation Vol. 80, pp. 1207-21, ISSN 00097322.

Pratty, F., Regar, E., Mintz, G.S., Arbustini, E., DiMario, C., Jang, I-K., Akasaka, T., Costa, M., Guagliumi, G., Grube, E., Ozaki, Y., Pinto, F. \& Serruys, P.W.J. (2010). Expert review document on methodology, terminology, and clinical applications of optical coherence tomography. European Heart Journal Vol. 31, pp. 401-415, ISSN 1520765X.

Raffel, O.C., Akasaka, T. \& Jang I-K. (2008). Cardiac optical coherence tomography. Heart Vol. 94, pp. 1200-1210, ISSN 1355-6037.

Raffy; O., Azarian, R., Brenot, F., Parent, F., Sitbon, O., Petitpretz, P., Hervé, P., Duroux, P., Dinh-Xuan, A.T. \& Simonneau G. (1996). Clinical significance of pulmonary vasodilator response during short-term infusion of prostacyclin in primary pulmonary hypertension. Circulation Vol. 93, pp. 484-488, ISSN 0009-7322.

Rabinovitch, M. (2008). Molecular pathogenesis of pulmonary arterial hypertension. Journal of Clinical Investigation Vol. 118, pp. 2372-2379, ISSN 0021-9738.

Regar, E., Schaar, J.A., Mont, E., Virmani, R. \& Serruys, P.W.J. (2003). Optical coherence tomography. Cardiovascular Radiation Medicine Vol. 4, pp. 198-204, ISSN 1522-1865.

Rich, S. (2006). The current treatment of pulmonary arterial hypertension. Time to redefine success. Chest Vol. 130, pp. 1198-1202, ISSN 0012-3692.

Rich, S. (2009). The effects of vasodilators in pulmonary hypertension. Pulmonary vascular or peripheral vascular?. Circulation Heart Failure Vol. 2, pp. 145-150, ISSN 1941-3289.

Rich, S., Pogoriler, J., Husain, A.N., Toth, P.T., Gomberg-Maitland, M. \& Archer, S.L. (2010). Long-term effects of epoprostenol on pulmonary vasculature in idiopathic pulmonary arterial hypertension. Chest Vol. 138, pp. 1234-1239, ISSN 0012-3692.

Rodés-Cabau, J., Domingo, E., Roman, A., Majo, J., Lara, B., Padilla, F., Anívarro, I., Angel, J., Tardif, J.C. \& Soler-Soler, J. (2003). Intravascular ultrasound of the elastic pulmonary arteries: a new approach for the evaluation of primary pulmonary hypertension. Heart Vol. 89, pp. 311-315, ISSN 1355-6037.

Sakao, S., Tatsumi, K. \& Voelkel, N.F. (2010). Reversible or irreversible remodeling in pulmonary arterial hypertension. American Journal of Respiratory Cell and Molecular Biology Vol. 43, pp. 629-634, ISSN 1044-1549.

Sanz, J., Kariisa, M., Dellegrottaglie, S., Prat-González, S., Garcia, M.J., Fuster, V. \& Rajagopalan, S. (2009). Evaluation of pulmonary artery stiffness in pulmonary hypertension with cardiac magnetic resonance. Journal of the American College of Cardiology: Cardiovascular Imaging Vol. 2, pp. 286-295, ISSN 1936-878X. 
Sanz, J., Fernández-Friera, L. \& Moral, S. (2010). Imaging techniques and the evaluation of the right and the pulmonary circulation. Revista Española de Cardiología Vol. 63, pp. 209-223, ISSN 0300-8932.

Saouti, N., Westerhof, N., Postmus, P.E., Vonk-Noordegraaf., A.V. (2010). The arterial load in pulmonary hypertension. European Respiratory Review Vol. 19, pp. 197-203, ISSN 0905-9180.

Sitbon, O., Humbert, M., Jais, X., Ioos, V., Hamid, A.M., Provencher, S. Garcia, G., Parent, F., Hervé, P. \& Simonneau G. (2005). Long-term response to calcium channel blockers in idiopathic pulmonary arterial hypertension. Circulation Vol. 111, pp. 3105-3111, ISSN 0009-7322.

Soto, F.J. \& Kleczka, J.F. (2008). Cardiopulmonary hemodynamics in pulmonary hypertension: pressure tracings, waveforms and more. Advances in Pulmonary Hypertension Vol. 7, pp. 386-393, ISSN 1933-088X.

Stergiopulos, N, Segers, P, \& Westerhof, N. (1999). Use of pulse pressure method for estimating total arterial compliance in vivo. American Journal of Physiology Vol. 276, pp. 424-428, ISSN 0363-6143.

Tatebe, S., Yoshihiro, F., Koichiro, S., Makoto, N., Saori, M., Kimio, S., Oikawa, M \& Shimokawa, H. (2010). Optical coherence tomography as a novel diagnostic tool for distal type chronic thromboembolic pulmonary hypertension. Circulation Journal Vol. 74, pp. 1742-44, 1346-9843, ISSN 1346-9843.

Tonelli, A.R., Alnuaimat, H. \& Mubarak, K. (2010). Pulmonary vasodilator testing and use of calcium channel blockers in pulmonary arterial hypertension. Respiratory Medicine Vol. 104, pp. 481-496, ISSN 0954-6111.

Vieira Costa, E.L., Jardim, C., Bassin Bogossian, H., Passos Amato, M.B., Ribeiro Carvalho, C., \& Souza, R. (2005). Acute vasodilator test in pulmonary arterial hypertension: evaluation of two response criteria. Vascular Pharmacology Vol. 43, pp. 143-147, ISSN 1537-1891.

Wharton, J., Davie, N., Upton, P.D., Yacoub, M.H., Polak, J.M. \& Morrell, N.W. (2000). Prostacyclin analogues differentially inhibit growth of distal and proximal human pulmonary artery smooth muscle cells. Circulation Vol. 102, pp. 3130-36, ISSN 00097322.

Wharton, J., Strange, J.W., Møller, G.M.O; Growcott, E.J., Ren, X., Franklyn, A.P., Phillips, S.C. \& Wilkins M.R. (2005). Antiproliferative effects of phosphodiesterase type 5 inhibition in human pulmonary artery cells. American Journal of Respiratory and Critical Care Medicine Vol. 127, pp. 105-113, ISSN 1073-449X.

Yabushita, H., Bouma, B.E., Houser, S.L., Aretz, H.T., Jang, I.K., Schlendorf, K.H., Kauffman, C.R., Shishkov, M., Kang, D.H., Halpern, E.F. \& Tearney, GJ. (2002). Characterization of human atherosclerosis by optical coherence tomography. Circulation Vol. 106, pp. 1640-1645, ISSN 0009-7322. 


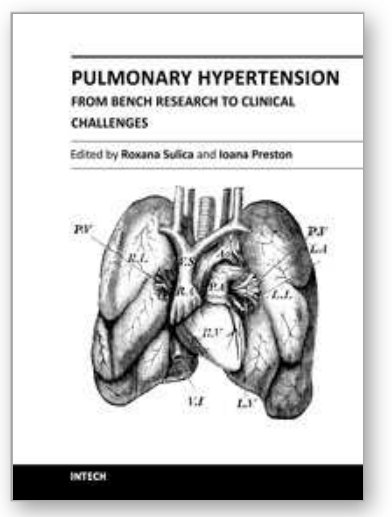

\section{Pulmonary Hypertension - From Bench Research to Clinical Challenges}

Edited by Dr. Roxana Sulica

ISBN 978-953-307-835-9

Hard cover, 326 pages

Publisher InTech

Published online 09, December, 2011

Published in print edition December, 2011

The textbook "Pulmonary Hypertension - From Bench Research to Clinical Challenges" addresses the following topics: structure and function of the normal pulmonary vasculature; disregulated cellular pathways seen in experimental and human pulmonary hypertension; clinical aspects of pulmonary hypertension in general; presentation of several specific forms of pulmonary hypertension, and management of pulmonary hypertension in special circumstances. The textbook is unique in that it combines pulmonary and cardiac physiology and pathophysiology with clinical aspects of the disease. First two sections are reserved for the basic knowledge and the recent discoveries related to structure and cellular function of the pulmonary vasculature. The chapters also describe disregulated pathways known to be affected in pulmonary hypertension. A special section deals with the effects of hypoxia on the pulmonary vasculature and the myocardium. Other three sections introduce the methods of evaluating pulmonary hypertension to the reader. The chapters present several forms of pulmonary hypertension which are particularly challenging in clinical practice (such as pulmonary arterial hypertension associated with systemic sclerosis), and lastly, they address special considerations regarding management of pulmonary hypertension in certain clinical scenarios such as pulmonary hypertension in the critically ill.

\section{How to reference}

In order to correctly reference this scholarly work, feel free to copy and paste the following:

Juan Grignola, Enric Domingo, Rio Aguilar-Torres and Antonio Roman (2011). Assessment of Structural and Functional Pulmonary Vascular Disease in Patients with PAH, Pulmonary Hypertension - From Bench Research to Clinical Challenges, Dr. Roxana Sulica (Ed.), ISBN: 978-953-307-835-9, InTech, Available from: http://www.intechopen.com/books/pulmonary-hypertension-from-bench-research-to-clinicalchallenges/assessment-of-structural-and-functional-pulmonary-vascular-disease-in-patients-with-pah

\section{INTECH}

open science | open minds

\section{InTech Europe}

University Campus STeP Ri

Slavka Krautzeka 83/A

51000 Rijeka, Croatia

Phone: +385 (51) 770447

Fax: +385 (51) 686166

\section{InTech China}

Unit 405, Office Block, Hotel Equatorial Shanghai

No.65, Yan An Road (West), Shanghai, 200040, China 中国上海市延安西路65号上海国际贵都大饭店办公楼 405 单元

Phone: +86-21-62489820

Fax: +86-21-62489821 
www.intechopen.com 
(C) 2011 The Author(s). Licensee IntechOpen. This is an open access article distributed under the terms of the Creative Commons Attribution 3.0 License, which permits unrestricted use, distribution, and reproduction in any medium, provided the original work is properly cited. 